\title{
Chronic pelvic pain associated with Nutcraker Phenomenon and pelvic congestion: a case report
}

\author{
(1) ILEANA SÄNGER ${ }^{1}$, (1) OSCAR ROMERO GURAL ${ }^{2}$, (D) CARLOS SARSOTTII', (D MARTINA SANTILLÁN ITURRES ${ }^{3}$ \\ ${ }^{1}$ Grupo de Diagnóstico y Rehabilitación de las Disfunciones del Piso Pelvico (GEDREP), Buenos Aires, Argentina \\ 2Phlebolinphology Section, Fundacion Favaloro, Buenos Aires, Argentina \\ ${ }^{3}$ Responsible of English Translation, Medicine Faculty, Buenos Aires University, Argentina
}

\begin{abstract}
The objective of this article is to present the case of a nulliparous female patient with a history of chronic pelvic pain associated with the nutcracker phenomenon (NCP), which was evaluated in our centre, with diagnosis and treatment using endovascular techniques and postoperative results. The case report of an 18-year-old female patient with a status of severe emotional and social deterioration resulting from four years of crippling pelvic pain along with numerous and unsuccessful surgical and medical support treatments is presented. In a review of the symptoms and complementary studies, the presence of pelvic congestion secondary to a NCP was identified as the origin of its clinic, an unusual pathology in nulliparous patients and with no consensus regarding on its optimal treatment. An embolization of the left gonadal vein (LGV) and left gluteal vein with sandwich technique was performed and the self-expanding vein stent was implanted in the left renal vein (LRV).
\end{abstract}

The patient recovered satisfactorily with immediate relief of pain.

Pelvic congestion syndrome should be considered in the differential diagnosis of chronic pelvic pain, even in nulliparous women. There are a wide range of treatment possibilities for this syndrome, depending on what causes it, clinical status and the anatomic characteristics of each patient. Although there is no standardized endovascular technique, in this case the embolization of the LGV and the left lower gluteal vein as well as the placement of a stent on the LRV, were proved to be safe and effective, with complete remission of pain. Additional studies would be useful to investigate the best treatment in cases of pelvic congestion and NCP.

Keywords: Pelvic pain; venous congestion; pelvic congestion syndrome; renal nutcracker phenomenon; renal nutcracker syndrome; renal vein; May-Thurner syndrome

\section{INTRODUCTION}

Chronic pelvic pain is a debilitating disease with considerable impact on quality of life and productivity. It is defined as nonmenstrual or non-cyclic pelvic pain, with duration of at least 6 months, sufficiently intense to interfere in daily activities and requiring clinical or surgical treatment. One of the main causes of chronic pelvic pain is pelvic congestion syndrome (PCS), characterized by varying degrees of pain, dysuria, dysmenorhea, dyspareunia, and vulvar congestion, often associated with vulvar varicose veins. ${ }^{1}$ A study by Asciutto et al. ${ }^{2}$ showed that the left

This article has been published as in ePub format previously with DOI number 10.34057/PPj.2020.39.04.AOP.A

Address for Correspondence: Ileana Sänger, Grupo de Diagnóstico y Rehabilitación de las Disfunciones del Piso Pelvico (GEDREP), Buenos Aires, Argentina E-mail: ilesaenger@me.com ORCID: orcid.org/0000-0003-0714-5010

Received: 28 July 2020 Accepted: 21 October 2020

${ }^{\circ}$ Copyright 2021 by the International Society for Pelviperineology / Pelviperineology published by Galenos Publishing House. 
gonadal vein (LGV) and right internal iliac vein are the most frequently involved in PCS ( $57.7 \%$ each).

Laboratory tests often reveal signs of microhematuria, which is possibly associated with nutcracker syndrome (NCS), an anatomic variant in which the superior mesenteric artery (SMA) and the aorta obstructed the left renal vein (LRV), causing reflux from this vein and the LGV. According to Robertson \& McCuaig NCS is a rare disease. ${ }^{3}$ Although the exact prevalence of NCS as a cause of PCS has not been quantified, the condition should always be suspected, in view of its importance in the presentation of PCS.

This article describes a case of PCS secondary to a Nutcracker phenomenon (NCP), diagnosed and treated with endovascular techniques in a private clinic at Ciudad Autónoma de Buenos Aires, Argentina.

The patient agreed to the publication of this case report and signed an informed consent form.

\section{CASE REPORT}

An 18-year-old female patient with a four years history of hypogastric and lumbar pain, was seen in our clinic. Her main complaint was visceral hypogastric pain, with no irradiation to any site other than the hypogastric area. It worsens with the standing position and movement, for this reason she was barely able to walk. Periods make this pain even worse and she referred that the only thing that alleviates her pain was the resting position. Quality of life assessment showed a young lady with a Karnofsky Index (KI)-5 performance status of 3/4 and a visual analogue scale (VAS) 10/10 in terms of pain. Physical examination was normal other than lower limb telangiectasias. She was free from lower limb oedema and other comorbidities. During all these years, she saw many specialists varying from gynaecology, rheumatology, gastroenterology, psychology and psychiatry. Transvaginal ultrasound could not be done because she was not sexually active. Abdominal ultrasounds that included Doppler scans and pelvic magnetic resonance imagings (MRIs) were considered normal.

She received many treatments including surgical procedures. She was treated by conservative treatment with phlebotonics, dienogest $2 \mathrm{mg} /$ day and many different analgesics. Two laparoscopies, by two different specialists, in order to rule out endometriosis were done, being both negative.

Next, a phlebotomography was indicated. It revealed a significant reduction of the LRV in the mid third, in the topography of the passage between the SMA and the aorta, providing evidence of Nutcraker phenomenon (Figure 1a and 1b). Also, a left common iliac vein compression by the right common iliac artery suggesting May-Thurner phenomenon (Figure 2) was observed. After these flebographies were done, in two different institutions, with the opinion that nothing was conclusive and could be done, a superior hypogastric plexus block under tomographic control was done. It also did not work. After all this, she was confined at home under psychiatric treatment as she was seriously depressed

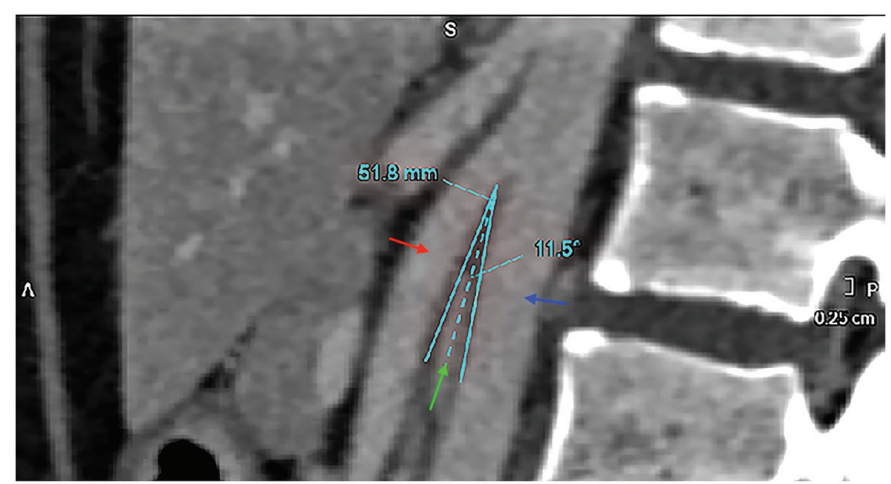

Figure 1a. Sagittal view phlebotomography, blue arrow aorta artery, red arrow superior mesenteric artery, in the middle with a green arrow left renal vein

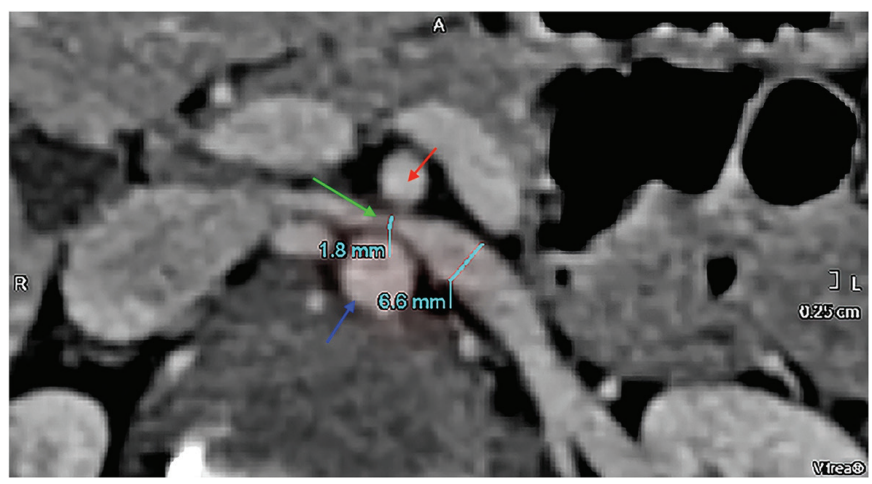

Figure 1b. Phlebotomography. Axial section. Green arrow shows LRV Stenosis, red arrow SMA, blue arrow aorta artery LRV: Left renal vein, SMA: Superior Mesenteric Artery

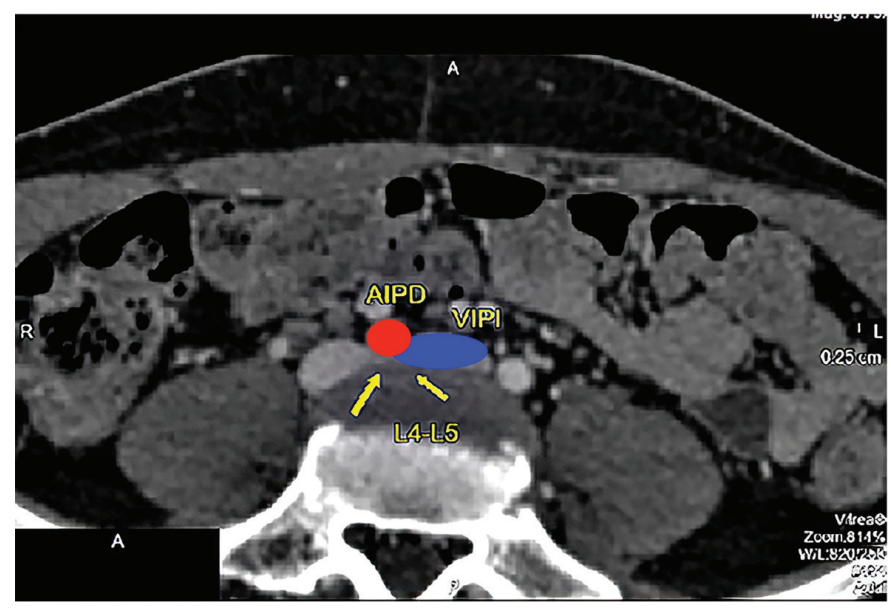

Figure 2. May-Thuner phenomenon, left common iliac vein (VIPI) compression (blue) by the right common iliac artery (AIPD) (red) AIPD: Arteria iliaca primitiva derecha (in Spanish); VIPI: Vena ilíaca primitiva izquierda (in Spanish) 
without resolution of pain.

On this first visit to our office, with us the exactly $80^{\text {th }}$ physician consulted, her parents let us know that besides looking for our opinion, and because of a thorough google search, they have already scheduled a new consultation with another vascular surgical service. After seeing all the studies brought by the patient and examining her, we agreed with this, as for us the pain was probably related to a vascular condition because of its clinical characteristics and the NCP seen at the phlebotomography already done. Due to her condition of practically feeble, as she was defined by her psychiatrist. So, we seriously considered re-examining the vascular anatomy with a new plebography, looking for a possible surgical procedure and not to go for further medical treatment.

The last flebography clearly showed LGV insufficiency (Figures $3 a$ and $3 b$ ) and ipsilateral adnexal varicose veins suggesting PCS (Figure 4). Because of this, the decision of endovascular surgical treatment was offered to the patient and her family. At least primarily.

An endovascular resolution was performed by using a double approach (jugular and femoral veins). Local anaesthesia and IV sedation were used. At the femoral level a 7 Fr introducer and Pigtail catheter were placed for the phlebography. A $12 \mathrm{Fr}$ introducer was used through the internal jugular vein. Zip Wire, Amplatz guides and a right coronary catheter were used for LRV cannulation. Pressures of significant cavo-renal gradient (2 $\mathrm{mmHg}$ ) were ruled out. Phlebography with derivative pathway evaluation protocol at $360^{\circ}$, where sign of previous Nutcracker was seen, showed imprints of LRV, which evidences retrograde flux through ascending lumbar system and LGV. Signs of severe pelvic congestion from gonadal veins and left lower gluteal vein were also seen Figure 3a, 3b and 4. Initially the embolization of left gonadal and lower gluteal veins was performed, with the sandwich technique, using foam (etoxiesclerol 2\%)-coils-foam, Controlled Release Coils (Concerto .Medtronic) 18x40 cm (0.018) (Figure 5). LRV was implanted with a self-expanding nitinol vein $16 \times 60 \mathrm{~mm}$ stent (Abre ${ }^{\infty}$. Medtronic) Figure 6a and 6b. Control phlebography showed disappearance of the described collateral pathways and signs of pelvic congestion. Anticoagulation protocol was started with Rivaroxaban, $20 \mathrm{mg} /$ day for 6 months and anti-aggregation with Clopidogrel, 75 mg daily for 3 months.

There were no complications during the angiographic procedure or the immediate postoperative period. The patient recovered satisfactorily with immediate relief of pain.

At 6 months, the patient referred that she is fully satisfied with the treatment and she scored her pain $0 / 10$ in a VAS, and a

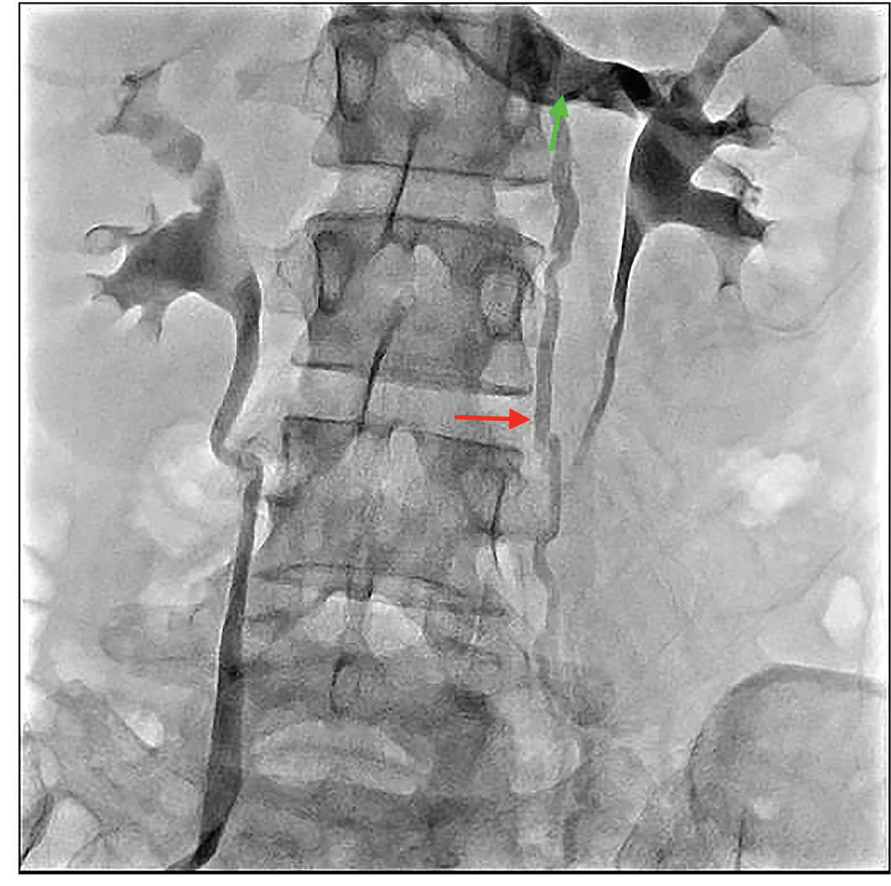

Figure 3a. Flebography. Green arrow shows enlarged LRV, red arrow shows left gonadal vein

LRV: Left renal vein

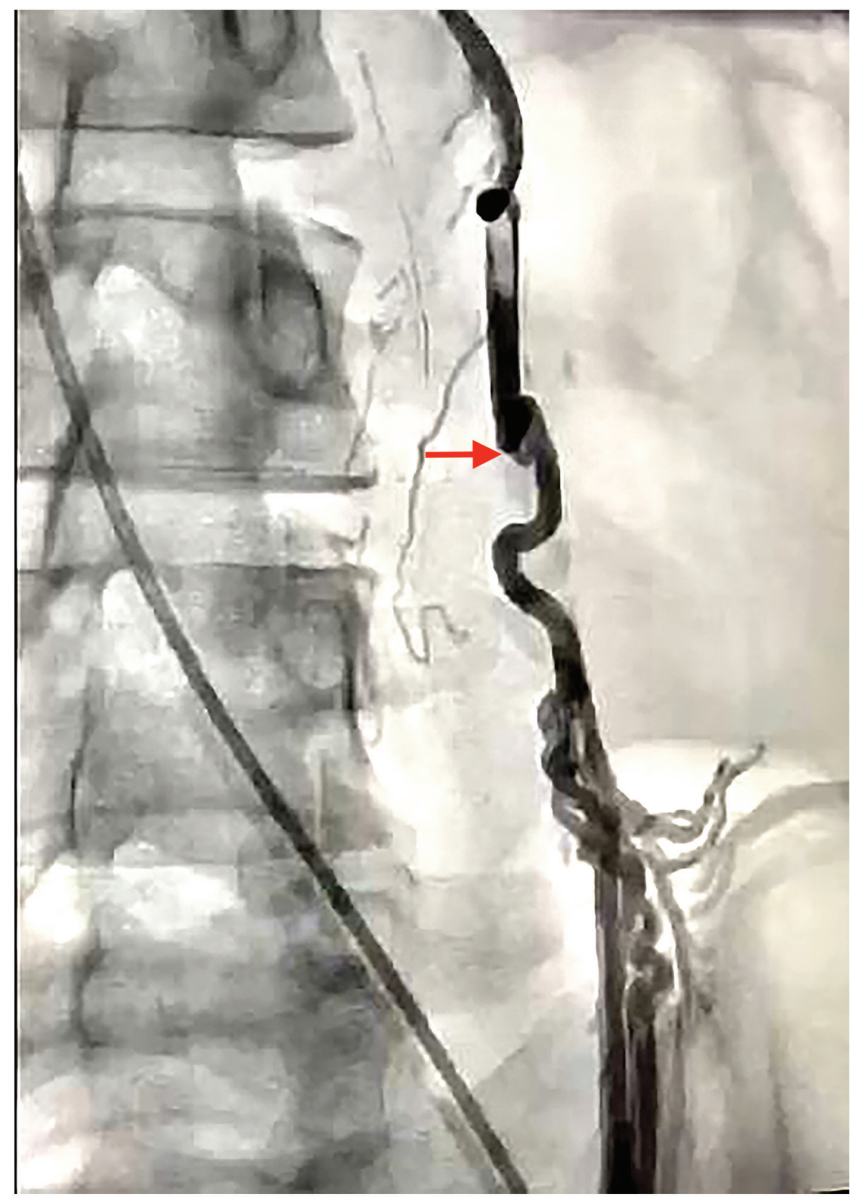

Figure 3b. LGV insufficient LGV: Left gonadal vein 


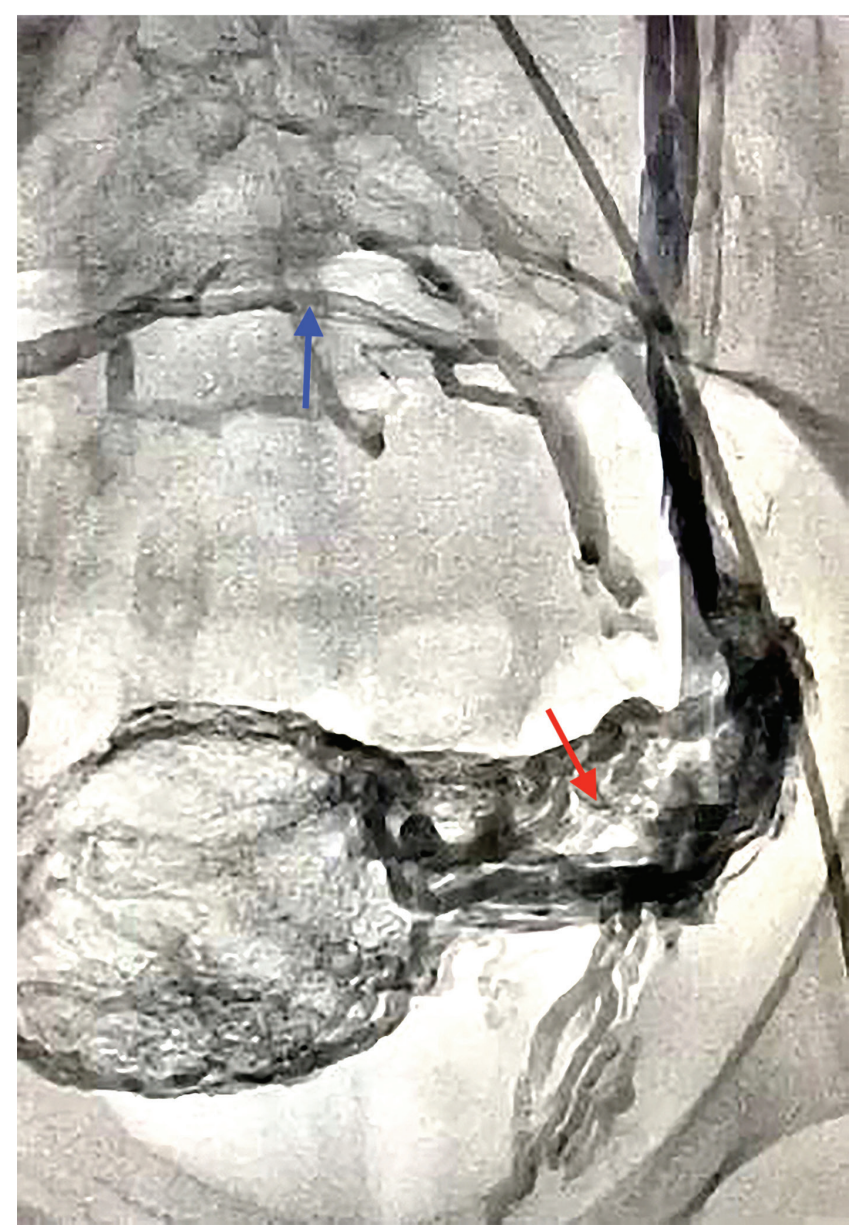

Figure 4. Red arrow on adnexal varicose veins, blue arrow on sacral collateral veins

performance status $0 / 4$ according to the $\mathrm{KI}$.

\section{DISCUSSION}

NCS generally affects women aged from 20 to 40 years, especially multiparous women. The venous reflux provokes varicose veins in the deep and superficial venous pelvic plexus and is responsible for a typical clinical status comprising left flank pain and chronic abdominal pain. In men, the syndrome may manifest in a similar way and has been described as one of the causes of varicocele. ${ }^{6-8}$ The NCP is due to compression of the LRV, most often between the aorta and the SMA, with debilitation of blood flow that is frequently accompanied by distension of the hilar portion of the vein. The NCS is the clinical equivalent of the $\mathrm{NCP}$, characterized by a complex of symptoms with substantial variations. The more common examples include haematuria and proteinuria, flank pain, pelvic congestion in female patients, and varicocele in male patients. ${ }^{7-8}$ The exact prevalence of NCS is unknown, partly because of an absence of definitive diagnostic criteria and the variability of symptomatic presentation. Patients can exhibit the condition at any age from infancy to the seventh

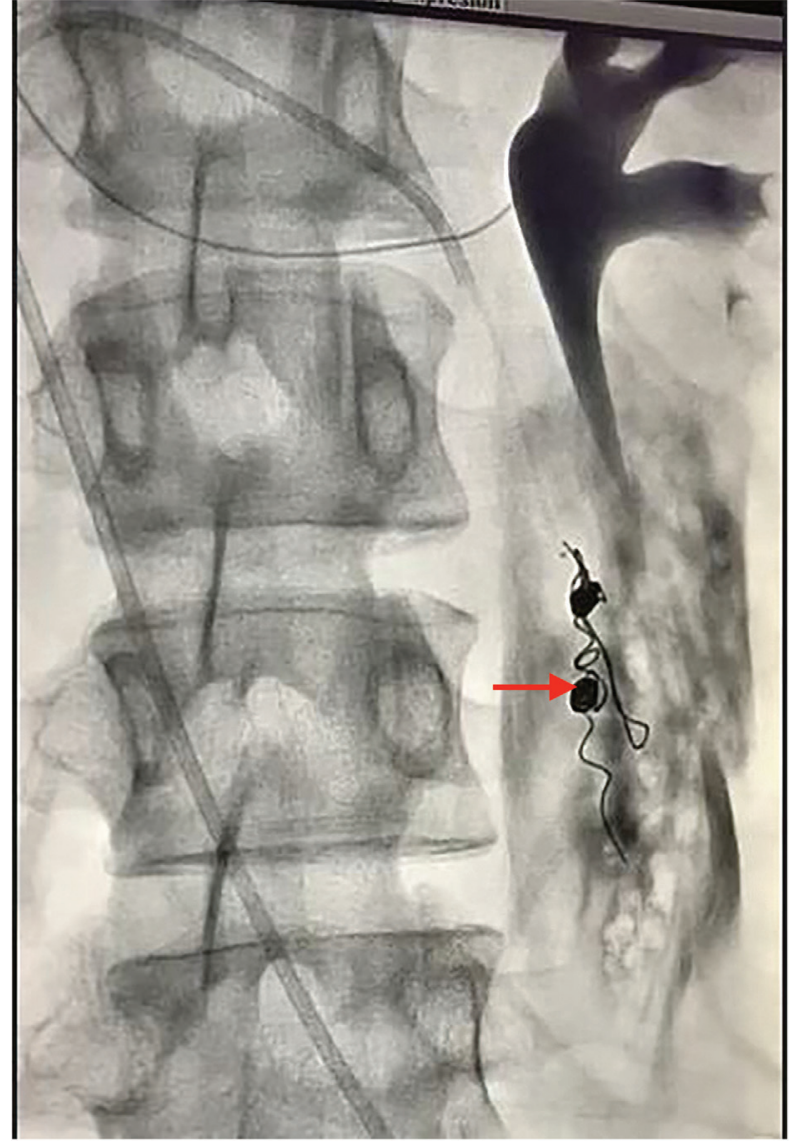

Figure 5. Embolization of the LGV, red arrow on the coils LGV: Left gonadal vein

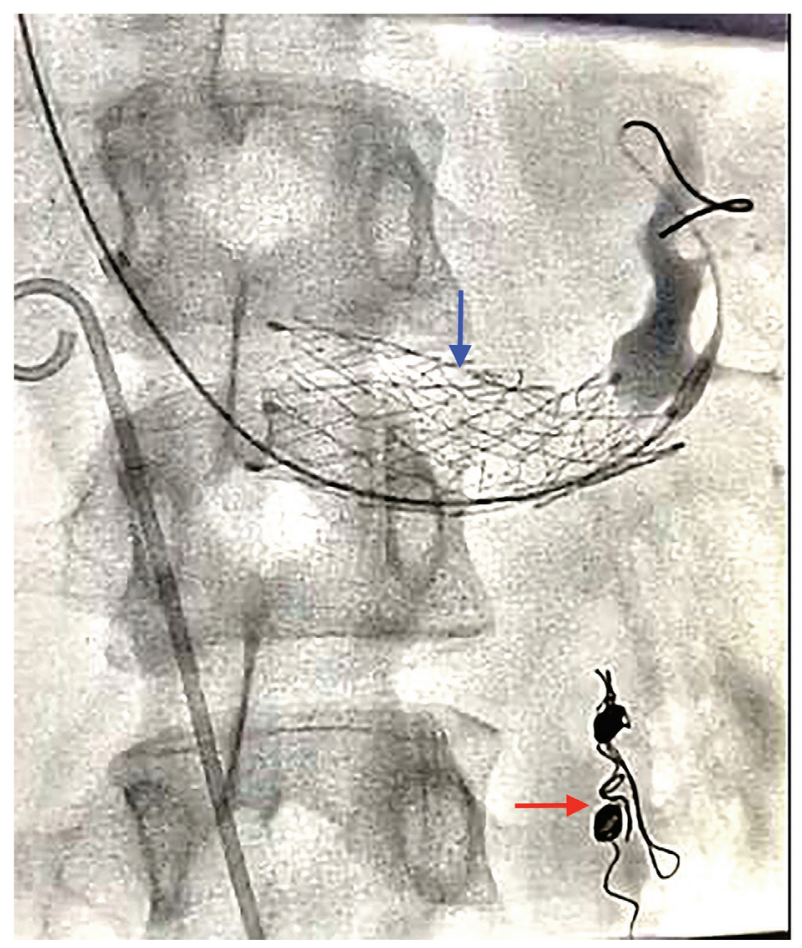

Figure 6a. Red arrow shows the coils on the LGV, blue arrow shows the stent on the LRV

LGV: Left gonadal vein, $L R V$ : Left renal vein 


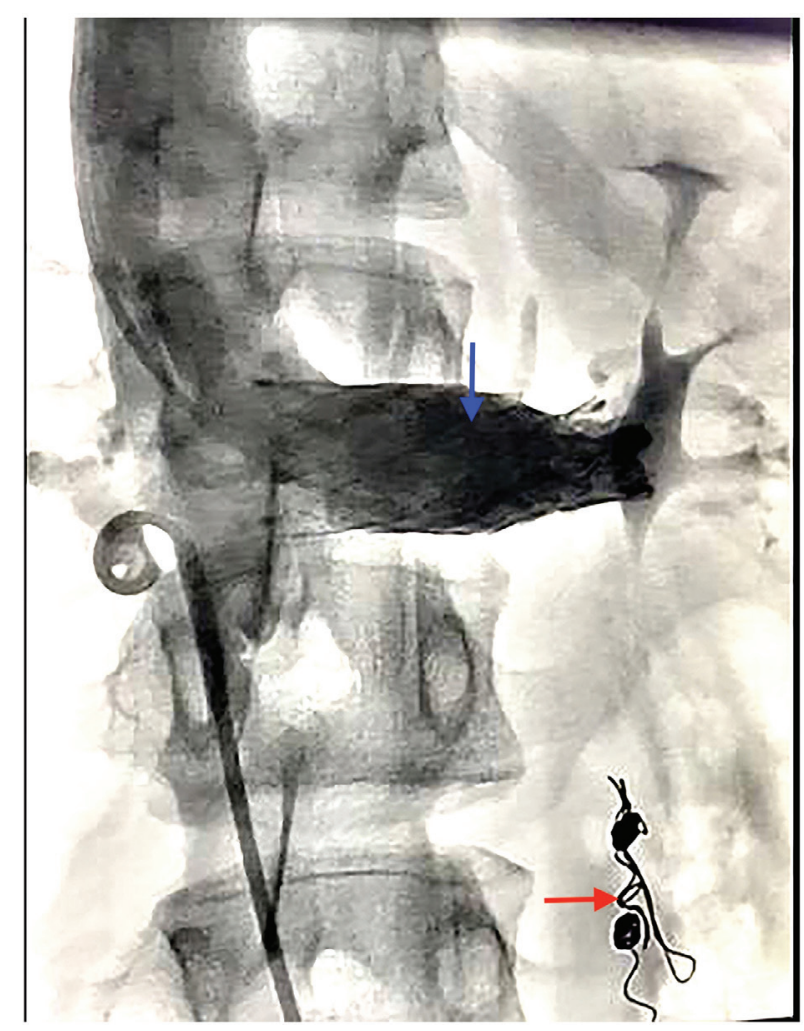

Figure 6b. Control phlebography, disappearance of the collateral pathways and signs of pelvic congestion, without contrast material on the LGV LGV: Left gonadal vein

decade of life, with peaks in youth (second to fourth decade), because of the rapid increase in height and development of vertebral bodies during puberty which can narrow the angle between the aorta and the SMA at middle-age. ${ }^{8-11}$ The prevalence of NCS was reported to be greater among women; however, later studies showed that this condition is equally prevalent among genders. ${ }^{6}$ In this particular case, and though she was a really young lady, because of her own description of the problem in the standing position, this made us pay attention to a possible vascular etiology.

Depending on the specific manifestations, NCS may be identified by a number of different medical specialists and, although it is associated with considerable morbidity, diagnosis tends to be difficult and is usually late. ${ }^{10}$ It can be confirmed with the results of imaging exams, including Doppler ultrasonography, tomography, MRI, phlebography, and intravascular ultrasonography.

Treatment for NCS varies depending on the patient's clinical severity and is reserved for symptomatic patients only. According to Macedo et al. ${ }^{12}$, treatment for the syndrome remains controversial, both for indication of treatment and for the best modality to be used for each patient as well. Options include conservative treatment, open surgery with section of the fibrous ligament between the SMA and the aorta, transposition of the LRV, kidney autotransplantation, and even nephrectomy.,12,13 These techniques can also be performed via open surgery or laparoscopic access, but experience is limited. ${ }^{14}$ Since 1996, endovascular approaches gained popularity, and have even been recommended as first-line treatment. ${ }^{15}$ Endovascular stent placement is usually preferable to open surgery, because of the long duration of renal congestion, the greater possibility of complications in these cases, and the need for extensive dissection in this type of operation. ${ }^{12}$ Additionally, there is the possibility of simultaneous embolization of the gonadal vein and/or sclerosis with polidocanol directly into the pelvic varicose veins during the procedure. Complications include stent migration, intra-stent restenosis, haemorrhage, and venous occlusion. ${ }^{10}$ With regard to LGV embolization, a literature review ${ }^{12}$ reports relief from symptoms in 56\%-98\%. In our patient, as we assumed that the presence of such invalidating symptoms of lower back and pelvic pain, were due the unusual kind of pelvic congestion associated with Nutcraker phenomenon we saw, which was confirmed by colour echodoppler, computed angiotomography and phlebography we counselled the patient for a more extended procedure, involving all the sites we recognized as abnormal. The embolization was performed with sandwich technique with foam (etoxiesclerol)-controlled coilsfoam and the stent implant dedicated to self-expanding vein in the LRV.

We decided to be conservative and wait about the observed in regard to May-Thurner phenomenon. This entity is a common but rarely diagnosed disorder involving left common iliac vein compression by the right iliac artery, with a suspected prevalence of $24 \%$ in the general population in retrospective studies of computed tomography scans, and $22 \%$ in cadaveric studies. ${ }^{16-17}$ Most commonly, the patient will present with symptoms of an underlying deep venous thrombosis, including pain, swelling, and discoloration of the extremity. ${ }^{16}$ May-Thurner syndrome is proposed to be the reason why deep venous thrombosis is five times more likely in the left lower extremity versus the right lower extremity. ${ }^{17}$ Patients may present as a spectrum of symptoms, from asymptomatic to extensive venous thrombosis in the left lower extremity and/or pulmonary embolism. ${ }^{18}$ It seemed that a high degree of clinical suspicion is critical to diagnose NCS as a cause of pelvic chronic pain in a young nulliparous women. There are a wide range of treatment possibilities, depending on clinical status and the anatomic characteristics of each case. In this case, the endovascular technique proved to be safe and effective. The LGV was embolized as well as a stent was placed on the LRV with complete remission of pain. 
There is no standard endovascular treatment. While some authors $^{12}$ supports indication of routine embolization of the gonadal vein combined with stenting of the LRV, others ${ }^{19}$ suggest using only the stent on the LRV and others only the embolization as initial treatment. In view of this, additional studies would be useful to investigate the best treatment in cases of NCS.

Finally, this case taught us that multidisciplinary approach is mandatory to all cases of chronic pelvic pain being simple or very complicated like this.

\section{ETHICS}

Informed Consent: The patient agreed to the publication of this case report and signed an informed consent form.

Peer-review: Externally peer-reviewed.

\section{DISCLOSURES}

Conflict of Interest: There are no conflicts of interest to declare.

Financial Disclosure: The authors declared that this study received no financial support.

\section{REFERENCES}

1. Nogueira AA, Reis FJC, Poli Neto OB. Abordagem da dor pélvica crônica em mulheres. Rev Bras Ginecol Obstet 2006; 28: 733-40.

2. Asciutto G, Asciutto KC, Mumme A, Geier B. Pelvic venous incompetence: reflux patterns and treatment results. Eur J Vasc Endovasc Surg 2009; 38: 381-6.

3. Robertson M, McCuaig R. Pelvic congestion syndrome. AJUM 2013; 16: 26-9.

4. Karnofsky DA, Burchenal JH. The clinical evaluation of chemotherapeutic agents in cancer. In: MacLeod CM, ed. Evaluation of chemotherapeutic agents. 1949; 191-205. New York: Columbia University Press.

5. Spitzer WO. State of science 1986: quality of life and functional status as target variables for research. J Chronic Dis 1987; 40: 46571.

6. Ferreira M, Lanziotti L, Abuhadba G, Monteiro M, Capotorto L, Spicacci JL. Chronic pelvic pain: the role of the nutcracker syndrome. J Vasc Bras 2008; 7: 76-9.
7. Correia T, Cardoso A, Soares R, et al. Síndrome de Quebra-nozes: A propósito de um caso clínico. Acta Urologica 2007; 24: 49-52.

8. Ananthan K, Onida S, Davies AH. Nutcracker Syndrome: An update on current diagnostic criteria and management guidelines. Eur J Vasc Endovasc Surg 2017; 53: 886-94.

9. He Y, Wu Z, Chen S, et al. Nutcracker syndrome-how well do we know it? Urology 2014; 83: 12-7.

10. Kurklinsky AK, Rooke TW. Nutcracker Phenomenon and Nutcracker Syndrome. Mayo Clin Proc 2010; 85: 552-9.

11. Gulleroglu K, Gulleroglu B, Baskin E. Nutcracker syndrome. World J Nephrol 2014; 3: 277-81.

12. Macedo GL, Santos MA, Sarris AB, Gomes RZ. Diagnóstico e tratamento da síndrome de quebra-nozes (nutcracker): revisão dos últimos 10 anos. J Vasc Bras 2018; 17: 220-8.

13. Avegerinos ED, McEnaney R, Chaer RA. Surgical and endovascular interventions for nutcracker syndrome. Semin Vasc Surg 2013; 26: 170-7.

14. Gunka I, Navratil P, Lesko M, Jiska S, Raupach J. Laparoscopic left renal vein transposition for nutcracker syndrome. Ann Vasc Surg 2016; 31: 219.e1-5.

15. Chen S, Zhang H, Shi H, Tian L, Jin W, Li M. Endovascular stenting for treatment of nutcracker syndrome: report of 61 cases with longterm followup. J Urol 2011; 186: 570-5.

16. Kibbe MR, Ujiki M, Goodwin AL, Eskandari M, Yao J, Matsumura J. Iliac vein compression in an asymptomatic patient population. J Vasc Surg 2004; 39: 937-43.

17. May R, Thurner J. The cause of the predominantly sinistral occurrence of thrombosis of the pelvic veins. Angiology 1957; 8: 419-27.

18. Thijs W, Rabe KF, Rosendaal FR, Middeldorp S. Predominance of leftsided deep vein thrombosis and body weight. J Thromb Haemost 2010; 8: 2083-4.

19. Costa LA, Silva OF Jr. Tratamento Endovascular da Síndrome do Quebra Nozes: relato de caso. J Vasc Bras 2014; 12: 247-51. 